\title{
AS RELAÇÕES DE GÊNERO NA LICENCIATURA EM MATEMÁTICA
}

\author{
RELACIONES DE GÉNERO EN EL GRADO DE MATEMÁTICA
}

GENDER RELATIONS IN THE MATHEMATICS DEGREE

\section{RESUMO}

No Brasil a abertura dos espaços escolares para as mulheres remonta ao século XIX, entretanto somente em sua segunda metade o público feminino teve acesso às universidades. Até então a elas eram destinados o zelo à família e os afazeres domésticos. Esta construção social que vincula às mulheres o cuidado com os outros permitiu associá-las rapidamente aos cursos de licenciatura. Atualmente, no país, elas ocupam grande parte das vagas dos cursos destinados à formação de professores. Entretanto, em algumas áreas, a exemplo da matemática, os números referentes à entrada e permanência dessas mulheres nem sempre é superior aos dos homens. Neste sentido, a presente pesquisa, de natureza qualitativa, tem como objetivo identificar as motivações encontradas por ambos os gêneros masculino e feminino, sobretudo o segundo, no que tange a escolha pela licenciatura em matemática e comparar as taxas de desistência e conclusão do curso desses dois grupos. Para isso, foi realizada uma pesquisa de campo envolvendo quatro turmas de uma universidade pública do estado da Bahia, com alunos ingressantes nos anos de 2014, 2015, 2016 e 2017. Os instrumentos de coleta de dados consistiram em um questionário aplicado aos participantes e em relatórios contendo a situação atual da matrícula desses discentes. Os resultados revelaram que tanto homens quanto mulheres optam pelo curso em virtude da facilidade que possuem em aprender a matemática ensinada na educação básica, contudo os primeiros costumam aparecer em número superior aos segundos, inclusive entre os formados.

Palavras-Chave: Relações de gênero. Instrução feminina. Licenciatura em matemática. 


\title{
RESUMEN
}

En Brasil, la apertura de espacios escolares para mujeres se remonta al siglo XIX, sin embargo, solo em la segunda mitad el público femenino tuvo acceso a las universidades. Hasta entonces, las mujeres eran responsables el celo por la familia y las tareas domésticas. Esta construcción social que establece relaciones entre mujeres y el celo a otras personas los hizo rápidamente asociados con cursos de pregrado. Actualmente, en el país, las mujeres ocupan una gran parte de las vacantes en cursos destinados a la formación de docentes. Sin embargo, en algunas áreas, como las matemáticas, los números que se refieren a la entrada y permanencia de las mujeres no siempre son más altos que los de los hombres. En este sentido, la presente investigación, de naturaleza cualitativa, tiene como objetivo identificar las motivaciones encontradas por los géneros masculinos y femininos, especialmente el segundo, con respecto a la elección de licenciatura en matemática y comparar las tasas de abandono y finalización de estos dos grupos. Para isso, foi realizada uma pesquisa de campo envolvendo quatro turmas de uma universidade pública do estado da Bahia con estudiantes que ingresaron en los años 2014, 2015, 2016 y 2017. Los instrumentos de recolección de datos consistieron en un cuestionario aplicado a los participantes e informes que contenían el estado actual de la inscripción de estos estudiantes. Los resultados revelaron que tanto hombres como mujeres eligen el curso debido a la facilidad que tienen para aprender las matemáticas que se enseñan en la educación básica, sin embargo, los primeros generalmente aparecen en mayor número que los segundos, incluso entre los formado.

Palabras clave: Relaciones de gênero. Instrucción feminina. Graduación em matematicas.

\begin{abstract}
In Brazil, the opening of school spaces to women dates back to the 19th century, however only in its second half did the female public have access to universities. Until then, zeal for the family and domestic chores were destined for them. This social construction that links women to the care for others allowed to quickly associate them with undergraduate courses. Currently, in the country, they occupy a large part of the vacancies in courses aimed at teacher training. However, in some areas, such as mathematics, the numbers referring to the entry and stay of these women are not always higher than that of men. In this sense, the present research, of qualitative nature, aims to identify the motivations found by both male and female genders, especially the second, regarding the choice for a degree in mathematics and to compare the dropout and completion rates of the course of these two groups. To this end, a field research was carried out involving four classes from a public university in the state of Bahia, with students that entering the years 2014, 2015, 2016 and 2017. The data collection instruments consisted of a questionnaire applied to the participants and in reports containing the current enrollment status of these students. The results revealed that both men and women, for the most part, opt for the course due to the ease they have in learning the mathematics taught in basic education, however the former tend to appear in higher numbers than the latter, even among graduates.
\end{abstract}

Keywords: Gender relations. Female instruction. Mathematics degree. 


\section{Introdução}

A discussão em torno da equidade de gêneros na Ciência tem ganhado notoriedade ao longo das últimas décadas. Contudo, destaca Batista et al. (2011), o número de pesquisas realizadas no Brasil acerca desse tema ainda necessita ser ampliado. De acordo com Lopes e Costa (2005) investigações dessa natureza lançam luz sobre uma falsa ideia amplamente propagada, embora às vezes de forma subliminar, da soberania intelectual dos homens com relação às mulheres. Uma análise superficial pode justificar a separação entre os gêneros nos altos postos de trabalho a partir da chamada meritocracia. Contudo, esse conceito só se aplica de forma devida a indivíduos que foram submetidos às mesmas condições. Não é o que ocorreu entre homens e mulheres ao longo da história da humanidade.

A discriminação sofrida pelas mulheres durante séculos é reflexo de uma sociedade instituída sob pilares patriarcais. Desde a Grécia Antiga, assiste-se à existência de relações desiguais que atribuem exclusivamente aos homens o direito ao conhecimento (CARVALHO; PEREIRA; PENEREIRO, 2016). Desta forma, sobressaem-se no âmbito da matemática exponentes como Tales, Pitágoras e Euclides, mas quanto aos nomes femininos pouco se tem a dizer. As mulheres gregas foram sucumbidas por uma cultura que lhes privava do direito a este tipo de saber. A ideia de meritocracia aqui, mais uma vez, não faz sentido algum. Ainda assim, do outro lado do Mediterrâneo, na cidade de Alexandria, no Egito, uma mulher de nome Hipátia fez história um pouco mais à frente: no século V. De acordo com Fernandez, Amaral e Viana (2019), ela se tornou professora de matemática e em suas pesquisas debruçou-se sobre a álgebra de Diofanto, os Elementos de Euclides e simplificou o trabalho de Apolônio sobre cônicas. Por ser pagã e colocar a racionalidade científica acima da fé foi perseguida e assassinada por cristãos.

Entre Hipátia e as outras mulheres matemáticas ${ }^{\mathrm{i}}$ que se tem conhecimento passaram-se, pelo menos, dez séculos (FERNANDEZ; AMARAL; VIANA, 2019). Esta lacuna revela as dificuldades impostas às mulheres quanto ao acesso à educação e ao conhecimento científico. Dentre os nomes femininos que lutaram contra a subjugação masculina destacam-se Maria Gaetana Agnesi, Sophia Germain, Mary Fairfax Greig Somerville, Sofia Kovalevskaya e Amalie Emmy Noether, todas elas representadas na figura 1. 
Figura 1 - Algumas mulheres matemáticas

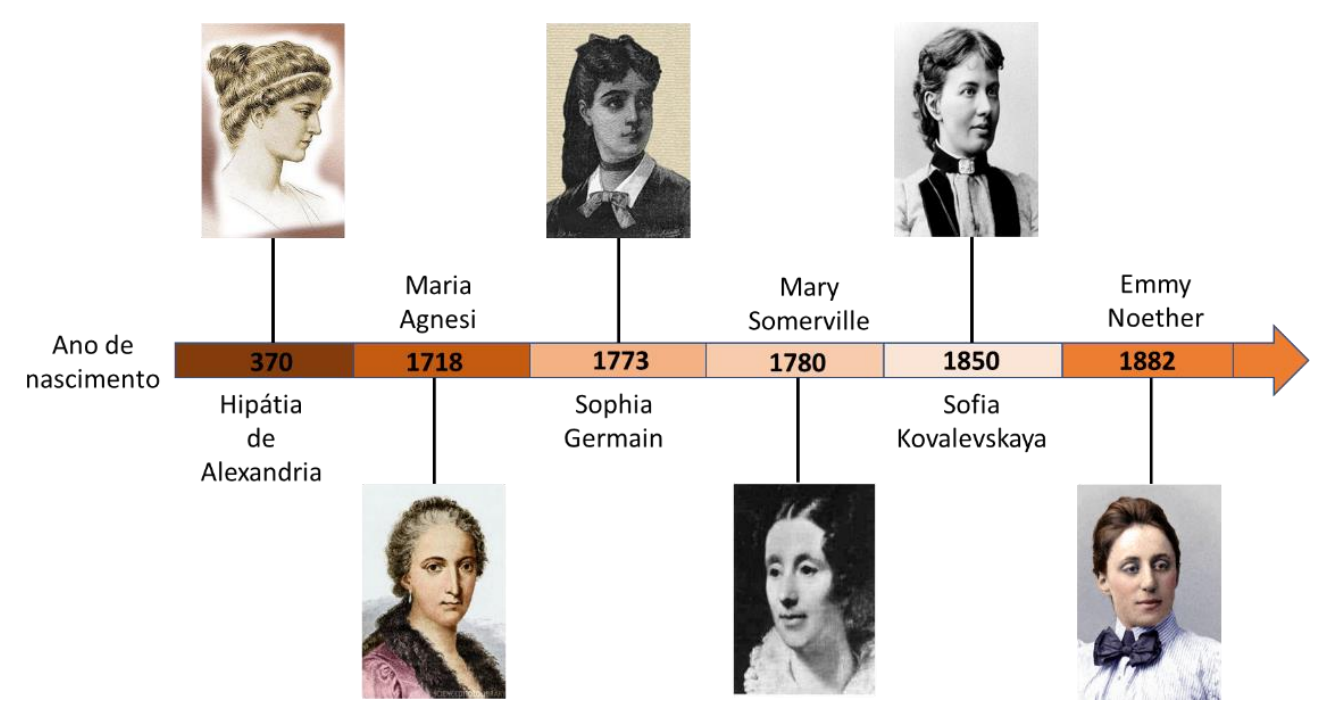

FONTE: Imagens extraídas dos sites www.wikipedia.org e http://jornalheiros.blogspot.com e agrupadas pelo pesquisador

Assim como Hipátia de Alexandria (370-415), todas as mulheres representadas na figura 1 foram, de alguma forma, perseguidas pela sociedade da época: a italiana Agnsei (1718-1799) não conseguiu ser professora simplesmente por ser mulher; a francesa Germain (1773-1831) teve a energia elétrica do seu quarto cortada, por seus pais, para que ela não tivesse condições de estudar; a escocesa Somerville (1780-1832) teve que enfrentar a resistência da própria família para poder avançar nos estudos; a russa Kovalevskaya (1850-1891) precisou sair do próprio país, pois as universidades russas não aceitarem mulheres; a alemã Noether (18821935) não teve permissão para assistir aulas como aluna regular em universidades alemãs, apenas como ouvinte (EVES, 2011). Esses fatos tornam compreensíveis, por exemplo, a escassez de teoremas que levam nomes femininos. A elas não foram dadas as devidas oportunidades de desenvolverem seus estudos e concorrerem em pé de igualdade com os homens. Contudo, a despeito de todas as dificuldades que enfrentaram, essas mulheres deram estimáveis contribuições no campo do cálculo diferencial e integral, teoria dos números, equações diferenciais e álgebra (MOURA, 2015). No que diz respeito às mulheres matemáticas não europeias, pouco espaço lhes é dado na historiografia da matemática. No Brasil, os primeiros registros que se tem conhecimento acerca da presença de mulheres na matemática datam do século passado como será visto ainda neste texto. 
As consequências dos fatos apontados acima são observadas nos dias de hoje. De acordo com a Organização das Nações Unidas para a Educação, a Ciência e a Cultura, as mulheres representam apenas $28 \%$ dos pesquisadores de todo o mundo (UNESCO, 2018). Há oscilações entre a predominância masculina e feminina a depender da área de conhecimento. Mas, no que diz respeito à matemática, mundialmente, a participação das mulheres é inferior à dos homens. De acordo com Brech (2018), essa discrepância se acentua à medida em que se avança nos níveis acadêmicos. Por trás desses números encontra-se uma construção social que procurou ditar, durante muito tempo, o que cabe aos homens e o que cabe às mulheres. Nesse sentido, Barreto (2014), afirma que “os diversos estereótipos atribuídos aos gêneros moldam, definitivamente, o significado atribuído às ocupações e às carreiras, pois é comum o entendimento de que há carreiras mais afeitas às mulheres e carreiras propriamente masculinas". É preciso destacar, porém, que as mulheres não assistiram com passividade a imposição de relações desiguais firmadas sob uma perspectiva de gênero, sobretudo ao longo dos últimos séculos. Esse "despertar" feminino aproximou as mulheres de áreas tidas como predominantemente masculinas como, por exemplo, a matemática. No Brasil, observa-se essa aproximação a partir da segunda metade do século passado. Segundo Cavalari (2010), até a década de 1990 percebe-se uma predominância feminina entre os formandos dos cursos de licenciatura em matemática em três das quatro universidades estaduais paulistas: Universidade de São Paulo (USP), Universidade Estadual de Campinas (UNICAMP) e Universidade Estadual Paulista (UNESP). De acordo com Menezes (2019), na Bahia também se observa resultados semelhantes, mas desta vez relacionados aos estudantes ingressos no curso. Durante praticamente as quatro primeiras décadas que sucederam a criação do primeiro curso de licenciatura em matemática do estado, em 1943 na Universidade Federal da Bahia (UFBA), o número de mulheres matriculadas era superior ao dos homens. Em 1963, formou-se na UFBA aquela que veio a ser a primeira doutora negra em matemática do país: Eliza Maria Ferreira Veras da Silva. O seu doutorado foi concluído em 1977 pela Universidade de Montepellier, na França, e tratou de álgebras não associativas ${ }^{\mathrm{ii}}$.

Quanto à UFBA, na década de 1980, “fraturas de gênero começavam a ocorrer no espaço matemático baiano, espaço considerado, ainda hoje, como mais 'apropriado' ao ingresso dos homens" (MENEZES, 2019, p. 1069). Com o intuito de fortalecer as pesquisas em matemática no estado aportaram na capital Salvador matemáticos que, embora bem intencionados, eram oriundos de uma cultura que desconfiava da capacidade intelectual feminina.

Revista RBBA $\mid$ Revista Binacional Brasil Argentina 
O presente trabalho consiste numa pesquisa de campo, de natureza qualitativa, realizada em território baiano. Trata-se de uma investigação que visa identificar as motivações encontradas por ambos os gêneros masculino e feminino, sobretudo o segundo, no que tange a escolha pela licenciatura em matemática e comparar as taxas de desistência e conclusão do curso desses dois grupos. Os participantes são os discentes ingressos neste curso, em uma universidade pública do estado da Bahia, nos anos de 2014, 2015, 2016 e 2017. Como instrumentos de coleta de dados foi aplicado um questionário acerca do interesse dos participantes pelo curso e, além disso, foram obtidos e analisados alguns relatórios que contêm o status da matrícula de cada discente. As informações coletadas abrangem tanto os homens quanto as mulheres e foram analisadas sob uma perspectiva de gênero.

\section{O acesso das mulheres brasileiras ao conhecimento matemático}

Durante o período em que Brasil era colônia portuguesa, as mulheres não foram assistidas com a mesma instrução escolar oferecida aos homens. Somente as filhas dos latifundiários tinham acesso a algum tipo de instrução e por meio de aulas particulares. Segundo Almeida (2006, apud AMARAL; SANTANA; SANT'ANA, 2015), no que diz respeito à matemática, lhes eram apresentadas algumas noções de aritmética. As mulheres escravas ou oriundas de famílias de baixa renda ficavam de fora. Somava-se à questão de gênero a desigualdade social.

A independência do Brasil trouxe consigo algumas conquistas como o direito ao ensino primário a todo cidadão livre. Assim, no ano de 1827 foram criadas as primeiras escolas destinadas ao público feminino (MENEZES, 2015). No que diz respeito à matemática, ao contrário do que ocorria com os meninos, o ensino das meninas deveria ser desprovido de geometria plana e espacial. Contemplava apenas noções de aritmética. De acordo com Menezes (2015, p. 48), “as operações matemáticas fundamentais eram permitidas para que fossem utilizadas na economia doméstica (...) já para os homens eram permitidas as elaborações matemáticas mais complexas". Em outras palavras, o ensino ofertado aos meninos era mais vasto se comparado àquele destinado às meninas.

$\mathrm{O}$ acesso das mulheres ao ensino médio só veio a ocorrer oito anos depois, em 1835 , embora em quantidade pouco expressiva (SOIHET, 2000). E, destaca Cavalari (2010), no que 
tange o ensino superior a situação era bem agravante: só foi permitido às mulheres ingressar em universidades na segunda metade do século XIX.

No ano de 1879 foi publicado o decreto $n^{\circ}$. 7.247 de Carlos Leôncio de Carvalho que autorizou o acesso das mulheres aos cursos universitários (FERNANDEZ, AMARAL, VIANA, 2019). Setenta anos depois tem-se a primeira mulher brasileira com o grau de doutora em matemática: Maria Laura Mouzinho Leite Lopes, em 1949. No entanto, praticamente um século antes, já se tinha o primeiro doutor em matemática no Brasil: Manuel da Cunha Galvão (MARTINES, 2014). É importante destacar que no ano de 1847, quando Galvão recebeu o grau de doutor em Ciências Matemáticas, às mulheres ainda não era permitido o acesso ao ensino superior. A tabela 1 contém uma síntese das informações apresentadas acima.

\begin{tabular}{l|l}
\multicolumn{2}{c}{ Tabela $1-$ Acesso de mulheres à educação no Brasil } \\
PERÍODO & TIPO DE EDUCAÇÃO \\
\hline 1827 & Ensino primário \\
1835 & Ensino médio \\
1879 & Ensino universitário \\
1949 & $\begin{array}{l}\text { Brasileira Mouzinho }(1917-2013) \text { torna- } \\
\text { se primeira Doutora em matemática }\end{array}$
\end{tabular}

FONTE: Fernandez, Amaral e Viana (2019)

Mouzinho exerceu o magistério superior na Universidade Federal do Rio de Janeiro até o ano de 1969 quando se aposentou em ocasião das repressões instauradas no Brasil em virtude da ditadura militar (FERNANDEZ; AMARAL; VIANA, 2019). Com isso, ela abandona o Brasil e passa a desenvolver pesquisas, na França, sobre a Didática da Matemática. Assim, Mouzinho se torna "uma das mais importantes pesquisadoras em Educação Matemática no Brasil e no mundo" (FERNANDEZ; AMARAL; VIANA, 2019. p. 34).

O descompasso de quase um século que separa os doutoramentos de Galvão e Mouzinho encontra eco nos presentes dias. O número de homens com doutorado em Matemática ainda é superior ao de mulheres. Segundo Melo (2017), a quantidade de mulheres que atuam como professoras de matemática nas universidades é consideravelmente inferior à de homens. Em termos percentuais, no período de 2009 a 2014, no Brasil, aproximadamente $40 \%$ do corpo Revista RBBA $\mid$ Revista Binacional Brasil Argentina 
docente dos cursos de graduação em matemática era formado por mulheres, destaca Brech (2018, p. 2). Na pós graduação há uma queda nesse quantitativo. Somente em 2014 esse percentual era de $22 \%$.

Estes dados se tornam mais agravantes quando se investiga a presença das mulheres no corpo de pesquisadoras do Instituto Nacional de Matemática Pura e Aplicada (IMPA). De acordo com Souza (2018), há apenas uma mulher ocupando este espaço. Fenômeno semelhante é observado na Sociedade Brasileira de Matemática. Segundo Melo (2017, p. 190), “dos quatorze membros do Conselho Diretor, apenas três são mulheres”. Na Academia Brasileira de Ciências a situação não é diferente. Dos cem membros titulares que ocupam a cadeira de matemática, apenas cinco são mulheres (FERNANDEZ; AMARAL; VIANA, 2018). Outro exemplo emblemático, desta vez em um âmbito global, está associado à maior premiação conferida a membros da comunidade matemática: A medalha Fields. Desde a sua criação, em 1936, até os presentes dias somente uma mulher recebeu este prêmio: a iraniana Maryam Mirzakhani, em 2014. Em sua homenagem, o dia 13 de maio, dia do seu nascimento, passou a considerado o dia internacional das mulheres na matemática.

A despeito dos dados apontados acima, quando se observa a base da pirâmide da formação acadêmica ${ }^{\text {iii }}$ percebe-se, nos presentes dias, que o desequilíbrio entre o total de homens e mulheres é menor. De acordo com Casagrande e Souza (2016), em alguns casos o interesse feminino por cursos de licenciatura em matemática excedo o masculino, enquanto em outros casos se percebe o inverso. Os dados apontados por esses dois autores baseiam-se em uma pesquisa realizada em duas universidades: uma localizada no sul e a outra no nordeste do país.

\section{A instrução feminina como uma construção social}

De acordo com o censo educacional realizado no Brasil no ano de 2017, o número de meninas matriculadas na última série do ensino médio mostrou-se superior ao de meninos (INEP, 2019a). O mesmo ocorreu no ensino superior, tanto no que diz respeito à quantidade de ingressantes quanto ao número de concluintes (INEP, 2019b). Somente nos cursos de licenciatura, o censo da Educação Superior do ano de 2018 revelou que as mulheres representam 71,3\% das matrículas. Esses dados apontam para um aumento da instrução feminina ao longo deste século. Contudo, as suas origens remontam ao século passado. 
Conforme assinala Leta (2003), no século XX permitiu-se, de forma mais contundente, o acesso das mulheres ao conhecimento científico. Agrega-se a esse fato o crescimento do movimento feminista que trouxe à tona reivindicações quanto a equidade de gêneros nas relações de acadêmicas e de trabalho.

A partir de uma pesquisa realizada de 2014 a 2016, a UNESCO constatou que dentre as mulheres universitárias de 110 países e territórios dependentes, apenas 5\% optaram por cursos de matemática, ciências naturais e estatística. Ainda assim, dentre o total de alunos matriculados nesses cursos, a maioria é feminina: 55\% do total (UNESCO, 2018). Quando se restringe a análise às ciências exatas o panorama se altera. De acordo com Melo (2017), nesse caso, ainda se tem mais homens do que mulheres.

Segundo relatório da UNESCO (2018, p. 15), embora "as diferenças de gênero no desempenho em ciências e matemática parece ter se reduzido em muitos países nos últimos anos, como demonstrado em pesquisas nacionais de larga escala elas ainda não foram totalmente eliminadas". Há de se reconhecer, pontua Melo (2017), os resquícios de uma construção social que associou durante séculos o conhecimento matemático aos homens. Essa associação é passada de geração para geração e os seus primeiros sinais já são registrados na infância. De acordo com Neiva (2019), enquanto as brincadeiras dos meninos são constituídas por "blocos de montar, jogos de tabuleiro, videogames e outros tipos de atividades físicas que incitam o desenvolvimento do raciocínio lógico e das atividades cognitiva-motora” às meninas destinam-se "bonecas jogos de cozinha, jogos de maquiagens, roupinhas para as suas bebês". É importante destacar que a capacidade cognitiva dos indivíduos não está atrelada à sua condição de homem ou mulher, mas aos estímulos aos quais foram submetidos ao longo de sua formação.

Se, por um lado, o gênero biológico não interfere no desenvolvimento cognitivo, como pontua Melo (2017), por outro, ele demarca posições que separam os homens e mulheres. Com efeito, quando se pensa em instrução feminina, não se pode descartar que as

barreiras incluem responsabilidades domésticas e de cuidado, casamento e gravidez precoces, normas culturais que priorizam a educação dos meninos, instalações sanitárias inadequadas nas escolas, preocupações dos pais quanto à segurança das meninas no caminho de ida e volta da escola, e violência escolar relacionada ao gênero. (UNESCO, 2018, p. 18). 
Esses fatores revelam o quanto é complicado para as mulheres conciliar a sua formação intelectual e carreira profissional às suas ocupações enquanto filhas, mães e donas de casa. Além disso, destaca Cavalari (2010), a tradição histórica marcada pela presença maciça de homens nos altos postos de trabalho, retirou das mulheres os seus símbolos de inspiração e autoidentificação.

A associação da mulher à imagem de cuidadora (seja dos filhos, do marido e do seu próprio lar), permitiu associá-la rapidamente aos cursos de licenciatura. De fato, pontua Souza (2018, p. 2), há uma tendência em desenhar o magistério como um ofício desenvolvido de forma mais adequada "por alguém com instinto maternal, suspostamente, inerente a todas as mulheres". Essa ideia começou a ser propagada no final do século XIX e foi consolidada no século XX quando se deu a redução do interesse masculino pela docência (ALMEIDA, 1998). Com a criação dos cursos de licenciatura no Brasil e com a abertura das universidades às mulheres, passa a ocorrer no país a chamada "feminização" do magistério. Desta forma, se reforça nas mulheres a opção imediata pela sala de aula, quando formadas, em detrimento da continuidade dos estudos em níveis de pós-graduação (SOUZA, 2018).

Segundo dados do Censo da Educação Superior realizado no ano de 2018, no Brasil, o curso de licenciatura em matemática ocupa a terceira posição quanto ao número de matrículas dentre os cursos voltados para a formação de professores (INEP, 2019c). Porém no relatório divulgado não é possível inferir quantas dessas vagas são preenchidas por mulheres. No ano de 2016, a taxa de desistência na licenciatura em matemática atingiu a marca de 62,2\%, contabilizando homens e mulheres. As taxas de permanência e conclusão corresponderam, respectivamente, a $28,5 \%$ e $9,3 \%$. A despeito de não ter atingido a marca dos $10 \%$, a taxa de conclusão no curso foi a maior dentre todas compreendidas de 2010 a 2016.

No que tange as professoras de matemática recém formadas no Brasil, os dados do Exame Nacional de Desempenho de Estudantes (ENADE) do ano de 2016 revelaram que, em sua maioria, essas mulheres desejam de fato exercer o magistério. Entre os principais fatores que as levaram a escolher a licenciatura em matemática, foram apontadas a vocação à docência e a e influência de professores que tiveram ao longo da educação básica (INEP, 2018). As respostas apresentadas pelos homens foram praticamente as mesmas. 


\section{Metodologia}

A presente pesquisa envolveu 179 discentes de uma universidade pública da Bahia, localizada no interior do estado e denotada neste trabalho por IES-BA (Instituição do Ensino Superior situada na Bahia). Esses participantes compuseram o grupo de ingressantes no curso de licenciatura em matemática da IES-BA ao longo dos anos de 2014, 2015, 2016 e 2017.

Os primeiros dados coletados na investigação foram obtidos na própria sala de aula, ambiente natural dos participantes enquanto discentes do curso de licenciatura mencionado. Nos primeiros dias de aula, em cada um dos quatro anos, o pesquisador buscou interagir com estes rapazes e moças com o intuito de compreender as suas motivações quanto à escolha do curso de licenciatura em matemática da IES-BA. Foi aplicado um questionário que continha questões a esse respeito, além de perguntas referentes à formação escolar e a idade dos participantes.

O questionário é um instrumento de coleta de dados adequado quando se tem um número elevado de participantes. Ele foi aplicado em sala de aula e os presentes o responderam simultaneamente. O pesquisador manteve-se à disposição para dirimir as possíveis dúvidas. Dentre as vantagens da utilização desse tipo de instrumento, Goldenberg (2004) destaca a facilidade de sua aplicação e o grau de liberdade atribuído aos respondentes que podem expressar as suas opiniões no papel sem ter que encarar de forma direta o pesquisador. Dos 179 participantes, 111 aceitaram responder o questionário e o fizeram durante o período de aproximadamente uma hora.

Antes da aplicação do questionário, o pesquisador informou aos participantes o objetivo de sua pesquisa. Buscou observá-los e ouvi-los durante todo o período em que estiveram juntos. Porém, para evitar respostas enviesadas, ele afirmou que a investigação visava identificar as motivações destes discentes quanto à entrada no curso e não fez menções a um estudo sob uma perspectiva de gênero. Ademais, revelou-se que pretendia analisar as taxas de desistência, permanência e conclusão do curso ao longo dos anos seguintes. Sob a garantia do sigilo de dados pessoais, todos aceitaram participar.

Os dados que permitiram ao investigador chegar às taxas mencionadas acima foram obtidos junto à coordenação do curso, mais uma vez, sob a garantia de preservação das imagens dos discentes. Essa é uma das razões pelas quais o nome da universidade não aparece explicitamente neste texto. As outras causas estão relacionadas ao empenho dos docentes, e 
também dos discentes, para reduzir a evasão e retenção ao longo do curso e que muitas vezes não está refletido nas taxas analisadas. Contudo, esse é um tema que foge do escopo dessa pesquisa e, portanto, não será contemplado aqui.

O estudo da desistência, permanência e conclusão no curso foi feito a partir de dados numéricos, estabelecendo comparações entre o público feminino e o masculino. Em alguns casos, fez-se uma análise do que ocorreu somente com as mulheres (ou somente com os homens) ao longo dos quatro anos de investigação.

Essas informações foram obtidas por meio de relatórios que contém os nomes dos discentes que ingressaram em determinado ano e a situação atual de cada um deles. Contudo, durante a investigação, também se destaca o contato do investigador com esses participantes com o intuito de compreender os fenômenos investigados por meio "dos olhos dos pesquisados" (GOLDENBERG, 2004, p. 27). Buscou-se, nesta pesquisa, uma aproximação com esses atores "para extrair desse convívio os significados visíveis e latentes que somente são perceptíveis a uma atenção sensível" (CHIZZOTI, 2003, p. 221). Desta forma, a presente pesquisa tem uma abordagem qualitativa.

Na próxima seção são apresentados os dados obtidos. Para manter a privacidade dos participantes, eles são referenciados por meio de pseudônimos criados pelo investigador.

\section{Resultados e discussões}

O curso de licenciatura em matemática da IES-BA foi criado no ano de 2007. Anualmente são ofertadas cinquenta vagas que costumam ser preenchidas, atualmente, por meio do Sistema de Seleção Unificada (SISU). Nem sempre todas elas são preenchidas.

A princípio a seleção era feita por meio de exames vestibulares. Neste caso, os candidatos indicavam o curso de sua preferência no ato da inscrição para realização das provas. No SISU, essa escolha é feita posteriormente. Se, por um lado, o SISU contribui para a democratização do ensino superior; por outro não é raro encontrar estudantes matriculados em cursos que não escolheriam a princípio. Trata-se de cursos em que os discentes puderam se matricular a partir da nota obtida na prova de seleção utilizada no SISU, ou seja, no Exame Nacional do Ensino Médio (ENEM). Na presente pesquisa são apresentadas informações a esse respeito, no que tange os participantes. Para analisar a relação de cada um deles com o curso, é 
preciso saber se a licenciatura em matemática representa, de fato, o primeiro curso de interesse desses atores.

Durante os anos de 2014, 2015, 2016 e 2017, houve um total de 179 discentes matriculados, sendo 79 mulheres e 100 homens. Esses números encontram-se compatíveis com as considerações de Melo (2017) segundo o qual os homens ainda revelam maior interesse pelas ciências exatas se comparado às mulheres. O gráfico 1 apresenta um comparativo entre essas matrículas, mas distribuindo-as ao longo dos períodos citados.

Gráfico 1 - Quantidade de discentes matriculados no curso de licenciatura em matemática da IES-BA de 2014 a 2017

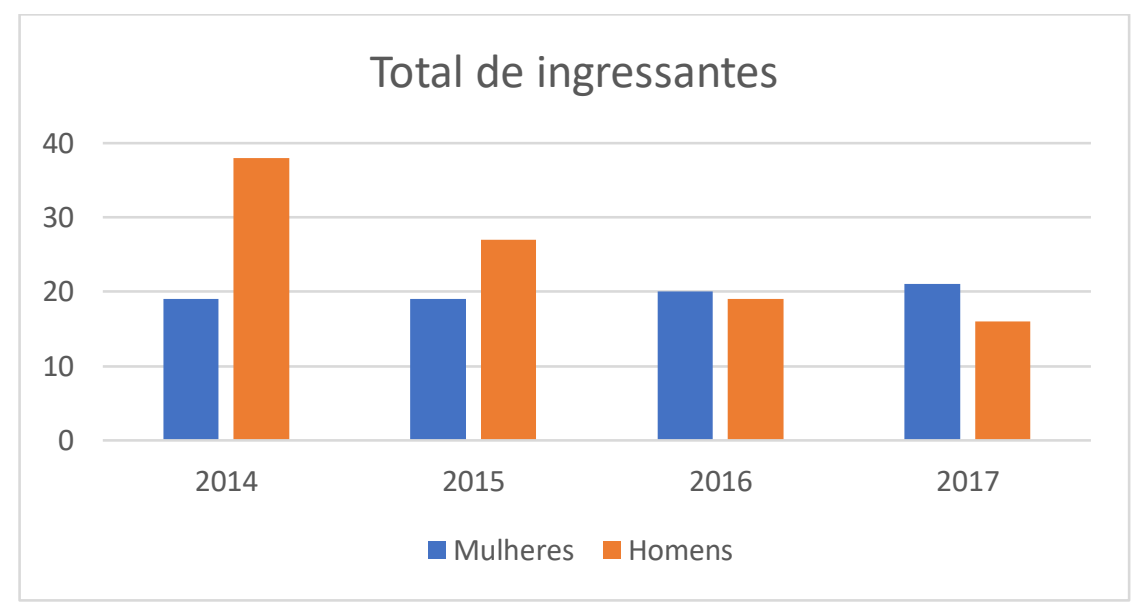

FONTE: Dados da pesquisa

Embora o Censo da Educação Superior de 2018 aponte a licenciatura em matemática como um curso com elevado número de matrículas dentre aqueles destinados à formação de professores (INEP, 2019c), o gráfico 1 revela que na IES-BA, de 2014 a 2017, houve uma redução da procura do curso por homens e um aumento pouco significativo do interesse feminino. Em termos gerais, nesta universidade, ocorreu um declínio no número de matrículas na licenciatura em matemática o que se revela preocupante tendo em vista a necessidade de se formar professores desse componente curricular, sobretudo longe dos grandes centros urbanos.

Interesse pela licenciatura em matemática. Os dados apresentados neste tópico dizem respeito aos 111 participantes que responderam ao questionário. Na turma de 2014, encontramse 32 desses participantes: 6 mulheres e 26 homens. Apenas um deles cursou o ensino médio na rede privada. Trata-se de um rapaz que tinha 19 anos no período em que o questionário foi aplicado. A média de faixa etária do público feminino e masculino respondente era, à época, de 20 e 22 anos, respectivamente. Para ambos os gêneros, masculino e feminino, o fator que mais 
lhes impulsionou a escolher o curso de licenciatura em matemática foi a facilidade em aprender os seus conteúdos. Abaixo, na figura 2, segue o relato da participante Verônica:

Figura 2 - Interesse da participante Verônica pela licenciatura em matemática

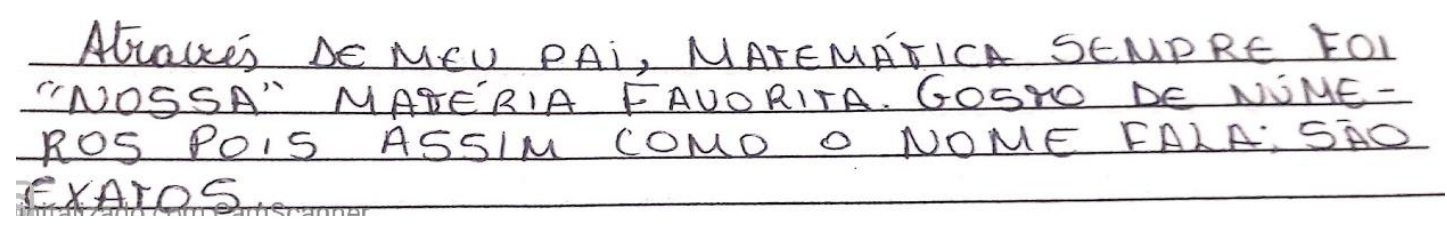

FONTE: Dados da pesquisa

Como se pode observar na figura 2, Verônica menciona o seu apreço pela matemática e lhe atribui, em certa medida, à influência de seu pai. Neste sentido, Cavalari (2010) assinala a importância de personagens que servem como fonte de inspiração para as pessoas. E destaca, em particular, a necessidade de as mulheres inspirarem umas às outras. No que diz respeito à matemática, porém, no caso de Verônica, a inspiração (ou melhor, motivação) veio de um homem.

Para os homens a opção pelo curso também proveio de suas relações prévias e "bem sucedidas" com a matemática. O comentário de Iago, retratado na figura 3, ratifica tais considerações:

Figura 3 - Interesse do participante Iago pela licenciatura em matemática

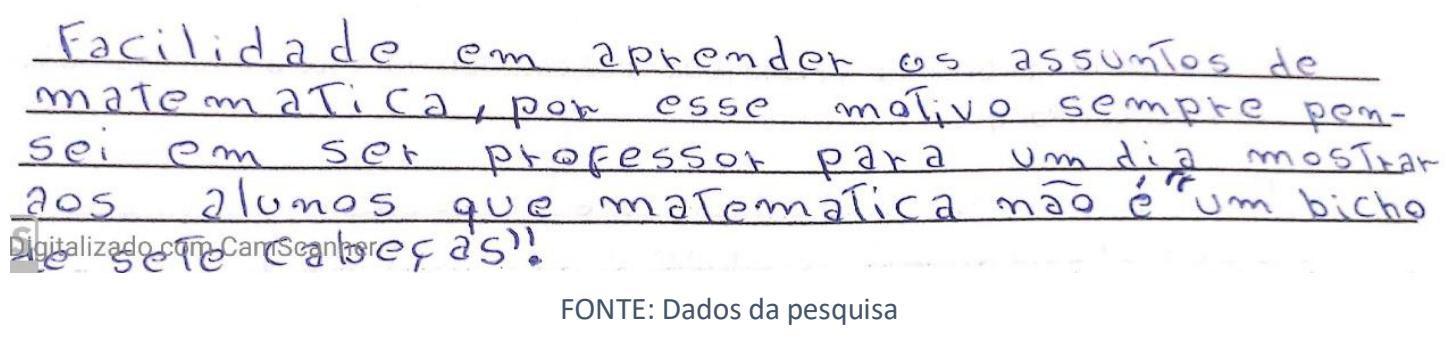

Um elemento que também aparece no comentário de Iago diz respeito à desconstrução da matemática como uma ciência inteligível em sala de aula. O participante assinala o seu desejo de exercer o magistério ao final do curso. Conforme revelaram os dados do ENADE de 2016, a maior parte dos formados em licenciatura em matemática têm, de fato, interesse pela docência (INEP, 2018). O participante Iago, em fase inicial do curso, aponta nesta mesma direção.

Contudo, nem todos os participantes mostraram pretensões em seguir carreira docente. Embora em menor quantidade, houve mulheres e homens que demonstraram um interesse "temporário" pela licenciatura em matemática. Para Rosa, a opção pelo curso deveu-se à 
necessidade de investir em sua formação em matemática "para tentar aprovação em outro curso". João fez considerações análogas. Uma parte do seu relato aparece na figura 4.

Figura 4 - Interesse do participante João pela licenciatura em matemática

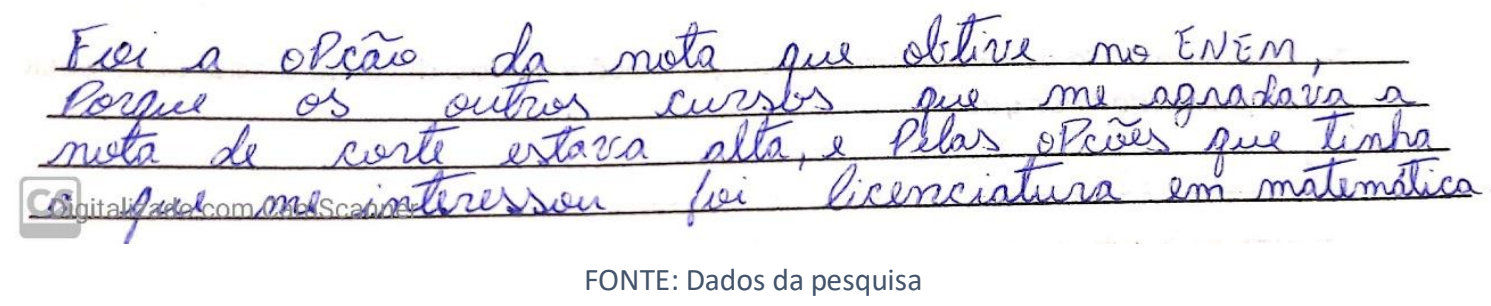

Ambos os participantes, Rosa e João, tendem a contribuir para o aumento da taxa de desistência do curso, à medida em que forem aprovados nos cursos de seus interesses (caso ocorra). De acordo com o Censo da Educação Superior, no ano de 2016, essa taxa já ultrapassava a marca de 60\% em todo o país (INEP, 2019c).

Na turma de 2015 houve 28 respondentes: 15 mulheres e 13 homens. Com relação ao público feminino, a média de faixa etária era, à época, de 23 anos. Apenas uma dessas mulheres cursou o ensino médio em escola particular. Todas as demais o fizeram em escolas da rede pública de ensino. De forma análoga à turma de 2014, algumas delas ressaltaram o interesse em mudar de curso. Mas, em sua maioria, sobressaiu-se o desejo pela licenciatura em matemática, sobretudo motivado pelos professores que tiveram na educação básica. A figura 5 apresenta o fator que influenciou a escolha da participante Maria Izabel.

Figura 5 - Interesse da participante Maria Izabel pela licenciatura em matemática

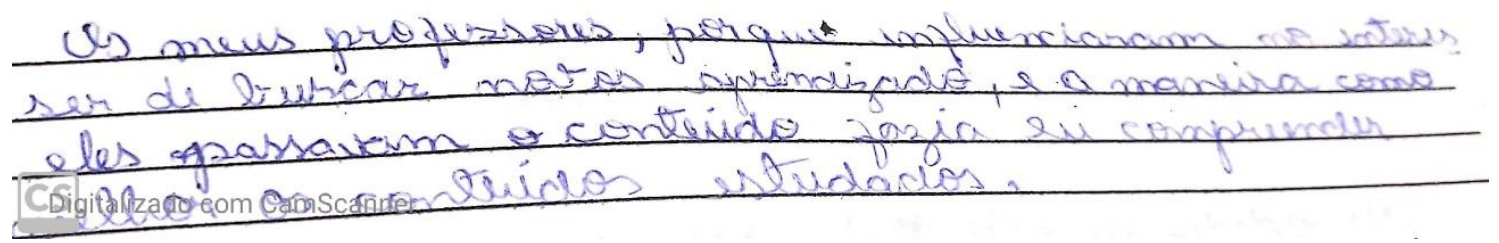

FONTE: Dados da pesquisa

Como é possível observar na figura 5, Maria Izabel destaca a importância dos professores na formação dos alunos. Para a participante, a metodologia de ensino adotada pelo professor exerce papel crucial no processo de aprendizagem. De fato, se, por um lado, é necessário ao professor o conhecimento matemático, por outro não se pode desconsiderar a formação pedagógica. Os cursos de licenciatura em matemática buscam contemplar essas duas dimensões. 
Em sua maioria, o público masculino também associou a escolha pela licenciatura em matemática aos seus professores da educação básica. A influência desses docentes também aparece nos dados do ENADE de 2016. Para grande parte dos alunos que concluíram a licenciatura em matemática na época, a opção pelo cursou deu-se em virtude das contribuições dadas por seus professores durante o ensino fundamental ou médio (INEP, 2018).

Além disso, os rapazes também destacaram, assim como na turma de 2014, a facilidade na compreensão dos conteúdos matemáticos como fator influenciador. Houve ainda quem relacionasse a facilidade com a matemática ao interesse em migrar para outro curso, como foi o caso do participante Lucas. Os seus comentários aparecem na figura 6.

Figura 6 - Interesse do participante Lucas pela licenciatura em matemática

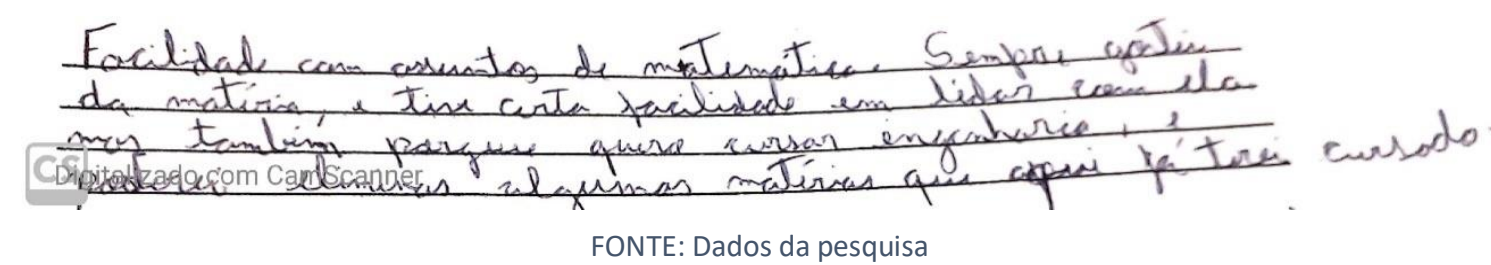

Assim como em alguns casos de 2014, também em 2015 o curso de licenciatura em matemática aparece como um trampolim que permitirá ao estudante obter aprovação em outro curso. Excluindo aqueles discentes que poderão ao longo desse processo manifestar o interesse em continuar no curso, esse fato já revela uma predisposição inicial para uma desistência futura. Soma-se a esses dados, aqueles participantes, homens e mulheres, que, embora em pequena quantidade, afirmaram cursar a licenciatura em matemática por ser o curso em que sua nota do ENEM lhes permitiu ingressar.

Na turma de 2016, 20 alunos responderam ao questionário: 9 mulheres e 11 homens. Desse total somente uma participante realizou o ensino médio na rede particular de ensino: uma garota de 18 anos à época. Quanto à média de faixa etária dos respondentes, tem-se 19 e 22 para mulheres e homens, respectivamente. Em ambos os gêneros, a opção pela licenciatura em matemática deve-se à facilidade em compreender os conteúdos matemáticos estudados na educação básica. Um dos participantes, Rivaldo, declarou que antes de ingressar na universidade já dava aulas particulares. O seu relato aparece na figura 7: 
Figura 7 - Interesse do participante Rivaldo pela licenciatura em matemática

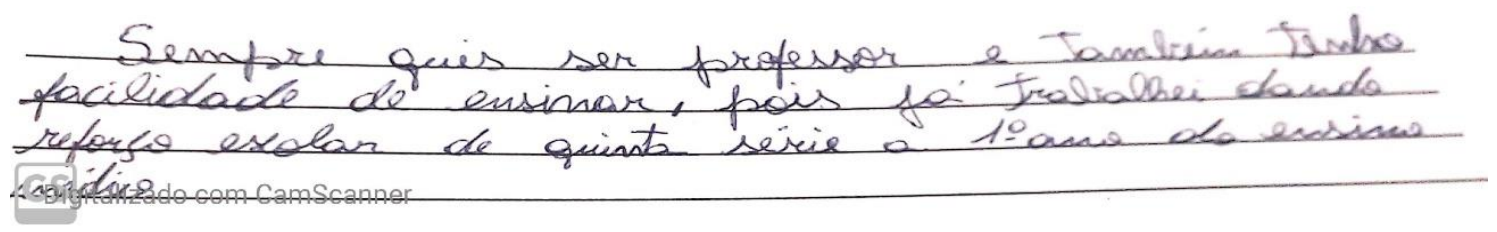

FONTE: Dados da pesquisa

A realização de aulas particulares mencionada por Rivaldo é uma prática comum em todo o país e suas origens são antiquíssimas. No Brasil-Colônia, quando as mulheres eram privadas de instrução escolar, algumas delas (oriundas de famílias abastadas), tinham aulas em suas residências (ALMEIDA, 2006 apud AMARAL; SANTANA; SANT'ANA, 2015).

Em alguns casos, os participantes tiveram que optar entre os cursos oferecidos no campus da IES-BA mais próximo de suas residências. Assim surgiu a opção pela licenciatura em matemática. Muitos deles são oriundos de cidades circunvizinhas à 6universidade ou, em alguns casos, residem na cidade onde se situa o campus. A figura 8 apresenta os comentários proferidos por Cláudia:

Figura 8 - Interesse da participante Cláudia pela licenciatura em matemática ${ }^{\text {iv }}$

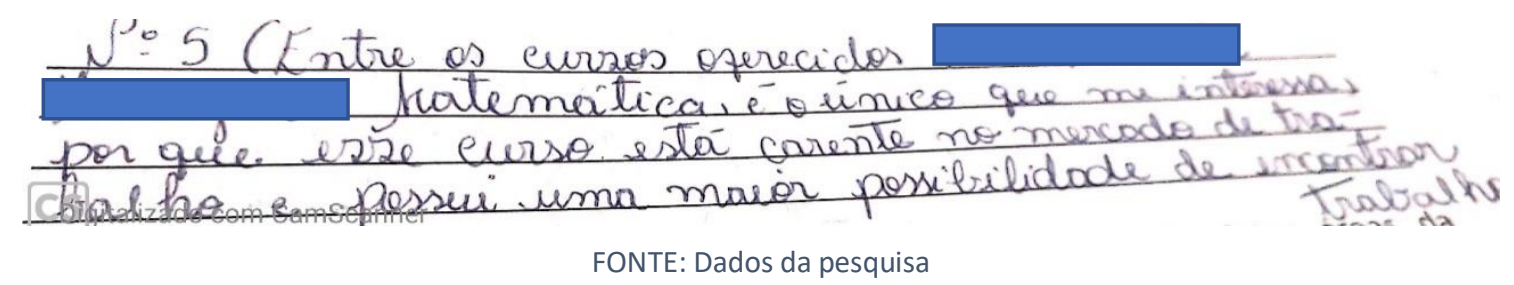

O relato de Cláudia diz respeito a uma dura realizada. Não obstante o avanço no número de matrículas nas licenciaturas em matemática em todo o país, registrado no Censo Educacional de 2018 (INEP, 2019c), ainda há vagas de professores de matemática que se encontram ociosas e que precisam ser preenchidas em todo o país.

Da turma de 2017, 32 responderam ao questionário: 17 mulheres e 15 homens, com médias de idade iguais a 21 e $2 \mathrm{q} 0$ anos, respectivamente. Desse total, apenas três cursaram o ensino médio na rede privada: um homem e duas mulheres. Ambos os gêneros associaram a opção pelo curso de licenciatura à facilidade com a matemática e à influência de seus professores da educação básica. Ao ser questionada a esse respeito, a participante Adilma apresentou a resposta retratada na figura 9. 
Figura 9 - Interesse da participante Adilma pela licenciatura em matemática

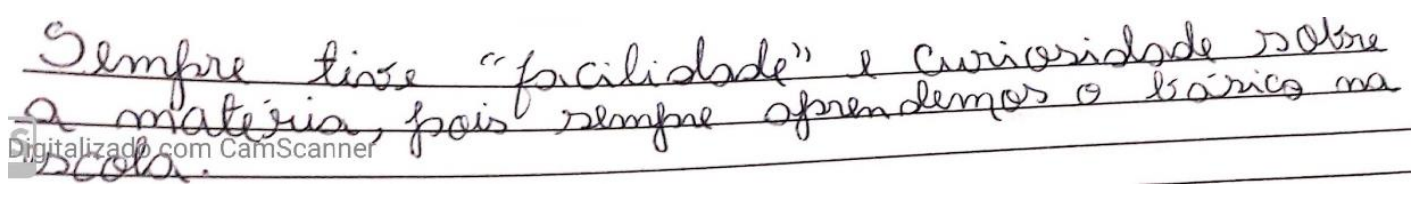

FONTE: Dados da pesquisa

A curiosidade mencionada por Adilma é essencial para o desenvolvimento de pesquisas em matemática. Não se deve ficar no superficial, no "básico", como assinalou a participante. É necessário ir mais além. A universidade é, de fato, um espaço para o aprofundamento das discussões, o que não significa dizer que se deve destinar à escolaridade básica abordagens acríticas ou rasas.

Outro comentário interessante foi apresentado por Plínio. Além de destacar a sua paixão pelo magistério, o participante fez referência à sua opção por uma universidade pública, como pode ser observado na figura 10.

Figura 10 - Interesse do participante Plínio pela licenciatura em matemática

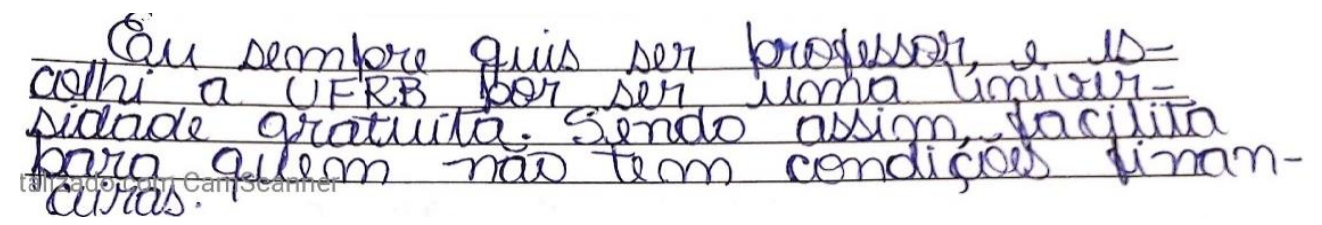

FONTE: Dados da pesquisa

As declarações de Plínio revelam que, possivelmente, ele teria dificuldades para se manter em uma universidade que não fosse pública. Evento semelhante pode ser inferido acerca da escolaridade básica dos participantes. Dos 111 discentes que responderam ao questionário, somente seis cursaram o ensino médio na rede particular de ensino.

Discentes desistentes. Dos 179 discentes matriculados durante os quatro anos investigados, 120 desistiram do curso, o que corresponde a uma taxa de 67\%. Esses dados estão compatíveis (embora ligeiramente acima) com a taxa nacional do ano de 2016 que foi de, aproximadamente, 62\% (INEP, 2019c). O gráfico 2 apresenta a distribuição dos valores ano a ano. 
Gráfico 2 - Quantidade de discentes matriculados que desistiram do curso de licenciatura em matemática da IES-BA de 2014 a 2017

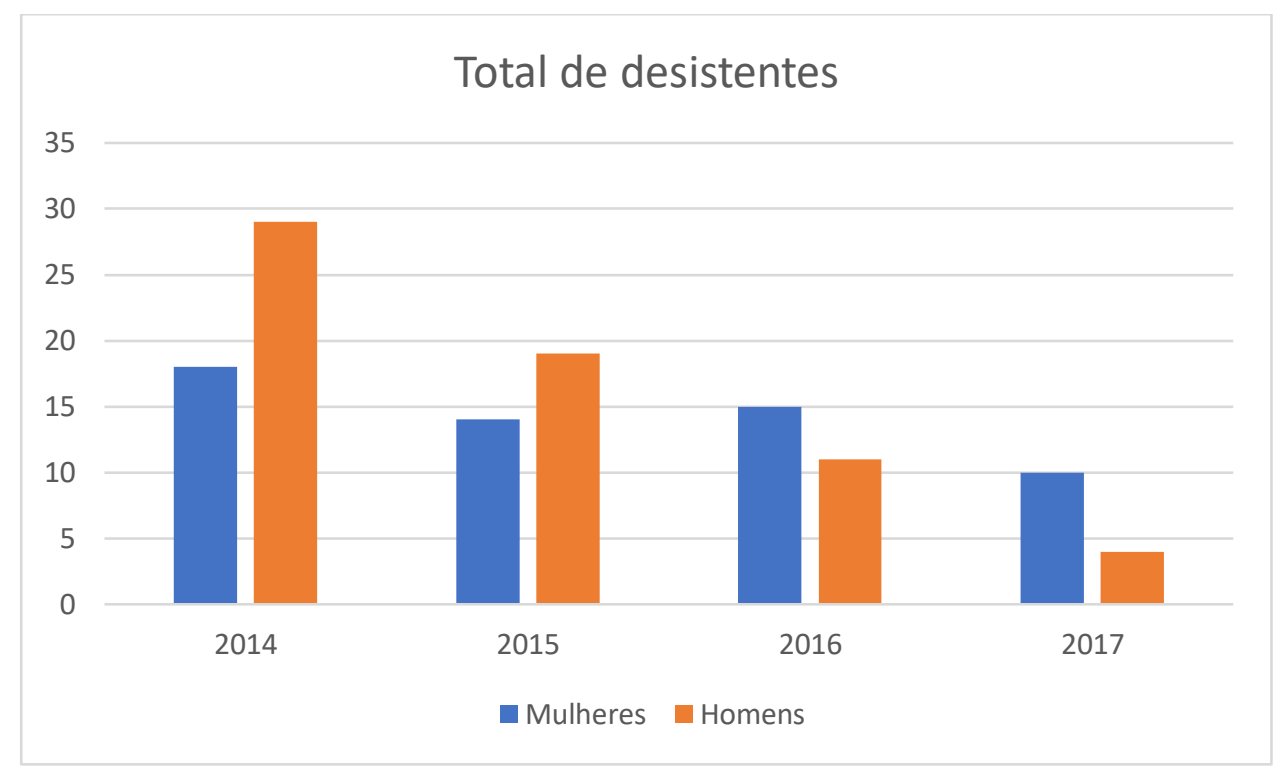

FONTE: Dados da pesquisa

Embora o gráfico 2 revele que, em valores absolutos, o número de homens que desistiram do curso foi superior ao das mulheres (63 e 57, respectivamente), para compreender esse fenômeno, sob uma perspectiva de gênero, é necessário comparar esses valores com a quantidade matrículas nesses dois grupos. Conforme já mencionado, de 2014 a 2017, 79 mulheres ingressam no curso. Aquelas que desistiram correspondem a aproximadamente $72 \%$ desse total, ou seja, um percentual bastante elevado. Quanto aos homens, ao longo desse período, foram registradas 100 matrículas. A quantidade de desistência corresponde a um total de 63\%: um percentual alto, mas ainda abaixo da média nacional registrada em 2016 (INEP, 2019c). Assim, é possível concluir que a incidência de desistência é maior entre as mulheres do que entre os homens.

Das 47 mulheres que responderam ao questionário, cinco delas haviam mencionado o desejo de migrar para outro curso. A licenciatura em matemática lhe daria as "bases" para isso. Todas elas fazem parte, hoje, da estatística de desistência. Embora não seja possível identificar as causas do abandono por parte das mulheres que participaram desta pesquisa, a UNESCO aponta a dificuldade enfrentadas pelo público feminino em conciliar as demandas do curso universitário com as tarefas domésticas e o cuidado com a família como um dos elementos que contribui para a impermanência das mulheres nos cursos (UNESCO, 2018). 
A partir do gráfico 2 também é possível concluir que, em valores absolutos, a desistência feminina não se deu por uma trajetória totalmente crescente ou descrente. De 2015 para 2016 houve um aumento no número de matrículas canceladas, enquanto que de 2014 para 2015 e de 2016 para 2017 houve uma redução. Quanto aos homens, observa-se durante todo o período da pesquisa uma redução, em termos quantitativos, no número de desistentes.

Para compreender melhor a desistência das mulheres ano a ano é necessário comparar a quantidade de matrículas no início do curso com a quantidade de matrículas canceladas. Em 2014, 2015, 2016 e 2017 o número de ingressantes do sexo feminino foi igual a 19, 19, 20 e 21, respectivamente. No que se refere à quantidade de desistência tem-se os seguintes números, na ordem: 18, 14, 15 e 10. Em termos percentuais tem-se os valores indicados no gráfico 3:

Gráfico 3 - Percentual de desistência das mulheres de 2014 a 2017

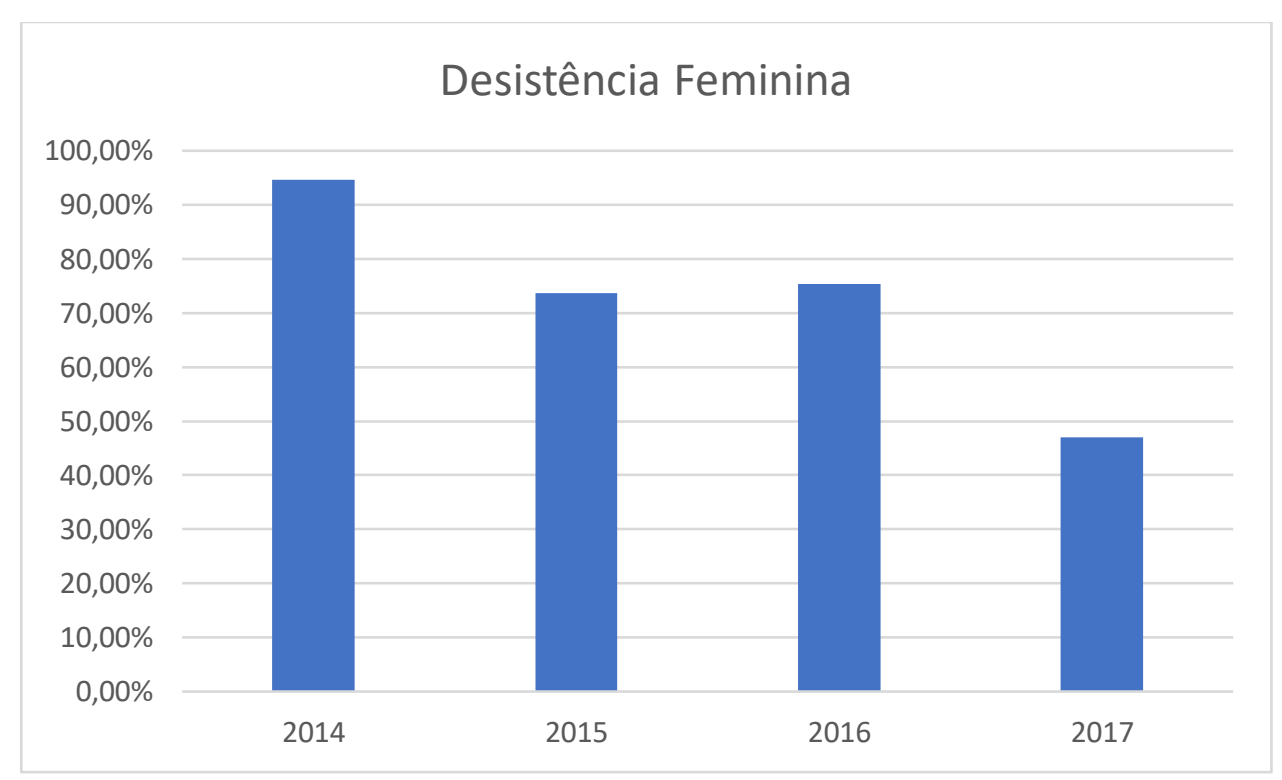

FONTE: Dados da pesquisa

Conforme revela o gráfico 3, a taxa de mulheres que desistiram do curso de licenciatura em matemática da IES-BA no ano de 2014 foi elevadíssima. Nos anos de 2015 e 2016 houve pequena variação percentual. Já o ano de 2017 foi aquele em que se observou um menor índice de desistência feminina. Foi a única vez, dentre os anos estudados, em que não foi ultrapassado o percentual de $50 \%$.

Discentes formadas e formados. No que diz respeito ao número de alunos que se formaram, o quantitativo é bem pequeno. Dos 179 alunos, somente 9 alunos concluíram o curso: três mulheres e seis homens. É preciso destacar, porém, que se trata de um curso com duração 
mínima de quatro anos e, portanto, é razoável considerar que os discentes que ingressaram em 2017 ainda estejam em fase de conclusão de curso.

Do total de 79 mulheres, 57 desistiram do curso e apenas 3 o concluíram. Há, portanto, 19 dessas matrículas ativas. A quantidade de alunas formadas ao longo desses anos corresponde a 3,79\% do total de alunas matriculadas. Esse valor está bem abaixo da média nacional do ano de 2016, isto é, 9,3\% a qual já se revela bastante preocupante (INEP, 2019c). Quanto aos homens, os seis formados de um universo de 100, correspondem a $6 \%$ do total. Embora a situação também seja crítica, ainda consegue superar os índices femininos.

Excluindo-se dessa análise a turma de 2017, tendo em vista a inviabilidade de conclusão do curso em um prazo inferior a quatro anos, os dados sofrem pequenas alterações. Neste caso, o total de discentes passa a ser igual a 142: 58 mulheres e 84 homens. Desta vez, o percentual de conclusão de curso dos públicos feminino e masculino passa a ser, nessa ordem, de 5,1\% e 7,1, respectivamente. Ambas as taxas continuam abaixo da média nacional registrada em 2016.

\section{Considerações finais}

Desde a chegada dos portugueses ao Brasil que as mulheres brasileiras foram privadas do conhecimento matemático e quando lhe tinham acesso, o ensino se dava de forma menos aprofundada comparando-se com os homens (MENEZES, 2015). Instaurou-se no país uma tradição centenária que delegava às mulheres a condição de donas de casa. Não que haja demérito algum em se dedicar aos cuidados do lar, o problema é quando essa opção não se trata de uma escolha, mas de uma imposição.

$\mathrm{O}$ século XX diferenciou-se daqueles que lhe precederam por oportunizar às mulheres o acesso à universidade. Era a brecha que faltava. Hoje, tanto o número de mulheres que ingressam quanto o número daquelas que concluem o ensino superior excede o dos homens (INEP, 2019b). Na corrida pelo acesso à educação, elas partiram várias “casas" atrás e hoje estão na dianteira. Contudo, quanto ao seu reconhecimento no mercado de trabalho e à equidade de oportunidades, a questão é bastante delicada e não há condições de explorá-la aqui. A luta não para.

No que diz respeito à matemática e às ciências exatas de modo geral, o interesse masculino ainda supera o feminino (MELO, 2017). Os dados apontados na investigação aqui relatada corroboram essa informação. De 2014 a 2017, o número de homens matriculados no curso de licenciatura em matemática da IES-BA foi superior ao de mulheres. No que diz Revista RBBA $\mid$ Revista Binacional Brasil Argentina 
respeito ao interesse dos participantes pelo curso, tanto mulheres como homens, apontaram a facilidade na compreensão dos conteúdos matemáticos e a influência de seus professores de matemática da educação básica. Esses dados revelam que, embora os públicos feminino e masculino sejam submetidos a estímulos diferentes ao longo de sua formação (NEIVA, 2019), quando resolvem cursar a licenciatura em matemática as motivações costumam ser as mesmas. Em ambos os casos, costuma-se ter jovens de 20 anos (em média), oriundos de escolas públicas, conforme mostraram os dados apresentados. A origem escolar dos participantes mostra que, em ambos os gêneros, tem-se na licenciatura em matemática, discentes não oriundos de famílias abastadas.

Embora em quantidade menor, houve participantes que sinalizaram o interesse em migrar de curso. Outros revelaram que a opção pela licenciatura em matemática proveio da pontuação que alcançaram no ENEM. Esses fatores revelam que nem sempre o curso em que eles se matricularam representa, de fato, aquele de sua preferência. Elementos desse tipo foram apontados por mulheres e homens e, possivelmente, contribuíram para o aumento da evasão ao longo do curso.

Em termos proporcionais, a desistência feminina também foi superior à masculina. Além de ingressarem em menor quantidade no curso, elas desistem em maior número percentual quando comparada aos homens. Porém, no ano de 2017, a taxa de desistência das mulheres foi inferior à marca dos 50\%, menor índice registrado por elas ao longo dos quatro anos. Espera-se que essa taxa continue decrescendo nos anos seguintes.

Com relação ao número de participantes que concluíram o curso, os dados são preocupantes: nove, sendo apenas um terço formado por mulheres. Esses números revelam a presença de fatores externos, possivelmente históricos, culturais e sociais, que dificultam mais a permanência e a finalização do curso por mulheres do que por homens. É preciso identificálos. Quanto aos fatores internos, caso existam, não estão vinculados a fatores biológicos no que diz respeito ao gênero (MELO, 2017), mas talvez a uma crença internalizada de que a matemática não é para as meninas.

\section{Agradecimentos}

Agradeço às professoras Maria Izabel de Araújo da Universidade do Estado da Bahia (UNEB) e Cláudia Santana da Universidade Estadual de Santa Cruz (UESC) por se disponibilizarem a ler este trabalho, apresentando críticas, sugestões e indicando outras leituras. Estendo este 
agradecimento à professora Tânia Gusmão da Universidade do Sudoeste da Bahia (UESB) pela amizade e confiança.

\section{Referências}

ALMEIDA, J. S. Mulher e Educação: a paixão pelo possível. São Paulo: Fundação da Editora da UNESP, 1998.

AMARAL, R. S.; SANTANA, I. P.; SANT’ANA, C. C. O ensino de matemática e a educação feminina: aritmética e geometria no curso primário da Bahia império-república (1827-1939). Jornal Internacional de Estudos em Educação Matemática, v. 8, n. 1, p. 107-127, 2015.

BARRETO, A. A mulher no ensino superior: distribuição e representatividade. Cadernos do GEA, n. 6, jul./dez. 2014

BATISTA, I. L. et al. Gênero feminino e formação de professores na pesquisa em educação científica e matemática no brasil. In: SIMPÓSIO LATINO AMERICANO E CARIBENHO DE EDUCAÇÃO EM CIÊNCIAS DO INTERNATIONAL COUNCIL OF ASSOCIATIONS FOR SCIENCE EDUCATION, 4., 2011, Londrina. Anais eletrônicos [...]. Londrina: ICASE, 2011. Disponível em: http://www.uel.br/grupo-pesquisa/ifhiecem/arquivos/BATISTA\%20et\%20al\% 202011.pdf. Acesso em: 13 de maio de 2020.

BRECH, CHRISTINA. O 'dilema Tostines' das mulheres na matemática. Revista Matemática Universitária, Rio de Janeiro, n. 54, p. 1-5, 2018.

CARVALHO, T. F.; FERREIRA, D. H. L.; PENEREIRO, J. C. Matemática, Mulheres e Mitos: causas e consequências históricas da discriminação de gênero. Educação Matemática Pesquisa, São Paulo, v.18, n.2, p. 571-597, 2016.

CASAGRANDE, L. S.; SOUZA, A. M. F. L. Para além do gênero: mulheres e homens em engenharias e licenciaturas. Estudos Feministas, Florianópolis, v.24, n.3, p. 825-850, set-dez 2016.

CAVALARI, M. F. Mulheres matemáticas: presença feminina na docência no ensino superior de matemática das universidades estaduais paulistas - Brasil. Revista Brasileira de História da Matemática, v. 10, n. 19, p. 89-102, 2010.

CHIZZOTI, A. A pesquisa qualitativa em ciências humanas e sociais: evolução e desafios. Revista Portuguesa de Educação, Braga, Portugal, v. 16, n. 2, p. 221-236, 2003.

EVES, H. Introdução à História da Matemática. Campinas: Editora Unicamp, 2011.

FERNANDES, M. C. V. A inserção e vivência da mulher na docência de matemática: uma questão de gênero. 2006. Dissertação (Mestrado em Educação) - Centro de Educação, Universidade Federal da Paraíba, João Pessoa, 2006. 
FERNANDEZ, C. S.; AMARAL, A. M. L. F.; VIANA, I. V. A história de Hipátia e de muitas outras matemáticas. Rio de Janeiro: SBM, 2019.

GOLDENBEERG, M. A arte de pesquisar: como fazer pesquisa qualitativa em ciências sociais. Rio de Janeiro: Editora Record, 2004.

INSTITUTO NACIONAL DE ESTUDOS E PESQUISAS EDUCACIONAIS ANÍSIO TEIXEIRA. Enade 2017: Relatório síntese de área - matemática (bacharelado/licenciatura). Brasília, 2018, 748 p.

INSTITUTO NACIONAL DE ESTUDOS E PESQUISAS EDUCACIONAIS ANÍSIO TEIXEIRA. Relatório SAEB 2017. Brasília, 2019a, 162 p.

INSTITUTO NACIONAL DE ESTUDOS E PESQUISAS EDUCACIONAIS ANÍSIO TEIXEIRA. Censo da Educação Superior 2018: Sinopse Estatística da Educação Superior 2018. Brasília, 2019b.

INSTITUTO NACIONAL DE ESTUDOS E PESQUISAS EDUCACIONAIS ANÍSIO TEIXEIRA. Censo da Educação Superior 2018: Divulgação dos Resultados. Brasília, 2019c.

LETA, J. As mulheres na ciência brasileira: crescimento, contrastes e um perfil de sucesso. Estudos Avançados, São Paulo, v. 17, n.49, p.271-284, 2003.

LOPES, M. M.; COSTA, M. C. Problematizando ausências: mulheres, gênero e indicadores na história das ciências. In: MORAES, Maria Lygia Quartim (Org.). Gênero nas fronteiras do Sul. Campinas: Pagu-Núcleo de Estudos de Gênero/UNICAMP, 2005. p. 75-83.

MARTINES, M. C. S. Primeiros Doutorados em Matemática no Brasil: uma análise histórica. 2014. Tese (Doutorado em Educação Matemática) - Instituto de Geociências e Ciências Exatas, Universidade Estadual Paulista Júlio de Mesquita Filho, Rio Claro, 2014.

MELO, C. I. B. Relações de gênero na matemática: o processo histórico-social de afastamento das mulheres e algumas bravas transgressoras. Revista Ártemis, v. 24, n. 1, jul-dez, p. 189200, jul-dez 2017.

NEIVA, G. Entrevista concedida a Isabela Giordan e publicada no site da Revista Quero Bolsa em 5 de mar. 2019. Disponível em: https://querobolsa.com.br/revista/homens-possuem-maisfacilidade-na-area-de-exatas-do-que-mulheres-informa-pesquisa. Acesso em: 13 de maio de 2020.

MENEZES, M. B. A matemática das mulheres: as marcas de gênero na trajetória profissional das professoras fundadoras do Instituto de Matemática e Física da Universidade da Bahia. (1941-1980). 2015. Tese (Doutorado em Estudos Interdisciplinares sobre Mulheres, Gênero e Feminismo) - Faculdade de Filosofia e Ciências Humanas, Universidade Federal Rural da Bahia, Salvador, 2015. 
MENEZES, M. B. Protagonismo Feminino na Matemática: criação e evolução do Instituto de Matemática da Universidade Federal da Bahia. Bolema, Rio Claro (SP), v. 33, n. 65, p. 10671086, dez. 2019.

MOURA, M. C. A participação da mulher na construção da matemática. 2015. Dissertação (Mestrado em Profissional em Matemática) - Departamento de Ciências Exatas e Naturais, Universidade Federal Rural do Semi-Árido, Mossoró, 2015.

ORGANIZAÇÃO DAS NAÇÕES UNIDAS PARA A EDUCAÇÃO, A CIÊNCIA E A CULTURA. Decifrar o código: educação de meninas e mulheres em ciências, tecnologia, engenharia e matemática (STEM). Brasília, 2018. 84 p.

SOIHET, R. A pedagogia da conquista do espaço público pelas mulheres e a militância feminista de Bertha Lutz. Revista Brasileira de Educação, Rio de Janeiro, n. 15, p. 118-133, set./dez. 2000

SOUZA, J. B. Mulheres na matemática: discurso e poder. In: Seminário Corpo Gênero e Sexualidade, 7., 2018, Rio Grande do Sul. Anais [...]. Rio Grande do Sul: FURG, 2018. Disponível em: https://7seminario.furg.br/anais. Acesso em: 13 de maio de 2020.

\section{SOBRE O AUTOR}

Elias Santiago de Assis é Doutor em Ciências da Educação, especialidade Educação Matemática, pela Universidade do Minho, Braga, Portugal. É licenciado em matemática pela Universidade Federal da Bahia (UFBA). Mestre em matemática pela mesma universidade. Atualmente é Professor Adjunto da Universidade Federal do Recôncavo da Bahia (UFRB)/Amargosa, Bahia, sendo Coordenador do Curso de Licenciatura em Matemática da UFRB. Endereço eletrônico: eliassantiago@ufrb.edu.br Orcid: https://orcid.org/0000-0002-5925-8810

Recebido em: 18/05/2020 Aprovado em: 12/06/2020 Publicado em: 01/07/2020

\section{Notas}

\footnotetext{
i Por "mulheres matemáticas" entende-se todas aquelas mulheres que se dedicaram ao estudo e ao desenvolvimento da Matemática.

ii Informações extraídas de http://ime.ufba.br/index.php/2020/01/30/primeira-doutora-negra-em-matematica-dobrasil-e-professora-aposentada-do-ime-ufba/. Último acesso em 17 de maio de 2020.

iii No que diz respeito à matemática.

${ }^{\text {iv }}$ Foram omitidas algumas partes do relato de Cláudia para evitar a identificação da IES-BA.
} 